\title{
Anatomical Studies on the Skull of the Domestic Rabbit (Oryctolagus cuniculus) With Special Ref- erence to the Hyoid Apparatus
}

\author{
Farag, F.M., Daghash, S.M. Mohamed, E.F., Hussein, M.M. \\ and Hagrass, S.M.
}

Faculty of Veterinary Medicine Cairo University

Anatomy and Embryology Department

With 9 figures

Accepted December 2011, accepted for publication February 2012

\section{Abstract}

The present work was conducted on 14 of local breed rabbits as well as on 12 New Zealand White rabbits. After preparing the specimens, different methods and techniques were conducted in a trial to produce clean bony specimens. The most suitable method used in the present investigation was cleaning by Dermestid Beetles then degreasing and bleaching using hydrogen peroxide. All characteristic features of the various parts of the axial skeleton in the rabbit were described and discussed with those recorded by other authors having performed earlier studies on rabbits and cats. Nomenclature in this thesis was adopted according to Nomina Anatomica Veterinaria (2005).

\section{Key words}

Rabbit, skull, hyoid apparatus.

\section{Introduction}

The domestic rabbit is used for many purposes including biomedical research, meat and fur (Shively, 1979). However, there has recently been a marked increase in its popularity as a companion animal and it has become the third most popular mammalian pet in the United Kingdom after the dog and cat (Nicholson, 2001 and Meredith, 2009). Consequently there has been an increase in the level of the veterinary care demanded by owners for this species (Meredith, 2009).

The fraudulent sale Because of its easy housing, feeding and very rapid reproductive ability, and rabbits provide a good source of high quality meat for a wide section of population. Some difficulty is encountered in distinguishing between rabbits and cats when skinned carcasses are exposed. So, the present inves- 
tigation covers not only the study of those morphological features peculiar to the skeleton of the rabbit but also the differential morphological features between it and the skeleton of the cats. This may serve as a guide for the detection of cats in lieu of rabbits.

\section{Materials and Methods}

1. The present work was carried out on twelve New Zealand White skeletally mature rabbits weighting $3-3.6 \mathrm{~kg}$, the skulls of the freshly slaughtered animals were removed and the tongue, muscles and eyes were removed as possible and the brain crushed using a wire stick (stirring) through the foramen magnum, then flushing the cranial cavity with water and repeating stirring and flushing until the brain had been removed.

2. The specimens were soaked for $12-24$ hours in cold water to which some ammonia had been added at a concentration of $0.03 \%$ (Hildebrand, 1968), before applying the cleaning techniques.

3. The specimens washed thoroughly in water and scraped with tooth brushes to remove the remaining soft tissues.

4. Three heads were dissected to describe the position and attachment of the hyoid bone. Another two specimen were sagittally sectioned to show the nasal cavity..

\section{- $\quad$ cleaning of the specimens} using Dermestid Beetles:

The Dermestid beetles are useful as a technique to clean bones, especially for the parts of the skeleton which are difficult to dissect by hand (Hefti et al., 1980).

1) Colony of dermestid beetles (Dermestis vulpinus) obtained from any dry carcass and placed into the bugging box within a layer of approximately 1 inch of saw dust or wood chips along the bottom of the box.

2) The prepared specimens were moderately dried in the open air for 5-6 hours before putting it in the bugging box.

3) For best results, the bugging box kept in a warm room of $\left(27^{\circ} \mathrm{C}\right.$ $29^{\circ} \mathrm{C}$ ) with a quantity of water being added to a cotton wad each day to maintain the beetle colony active and viable (Russell; 1947).

4) The beetle colony will completely corrode away the flesh from the specimen and leave an intact standing skeleton within a period of approximately 6 weeks.

\section{- Degreasing and Bleaching and drying:}

1)The bones were washed under running water then soaked for 2-3 days in deodorizing solution of 
$0.03 \%$ ammonia then another 2-3 days in $95-100 \%$ acetone for degreasing

2) This process was repeated 2-3 times until the greasy texture disappeared then washed in a slow stream of running water to remove ammonia or acetone residues, then dried in room temperature before dipped in the bleaching solution

3) For bleaching, bones were soaked in hydrogen peroxide $\left(\mathrm{H}_{2} \mathrm{O}_{2}\right)$ with a concentration of $3 \%-5 \%$ for five to seven days (Van Gestel, 2005).

4) The bleaching process was completed when the desired whiteness was obtained, then removed and soaked in fresh water for two days to eliminate odor and remove any chemical residue (Sullivan, Romney and October, 1999), then thoroughly dried for three days in open air The specimens were photographed using Olympus digital camera SP600UZ 12 mega pixel.

Results obtained in the present study were discussed and compared with those of other authors having performed earlier studies in rabbits and cats.

The nomenclature in this thesis was adopted according to the Nomina Anatomica Veterinaria (2005).

Moreover, some terms were adopted according to the available litera- tures when not recorded in the N.A.V.

\section{Results}

Skull: the skull of rabbit has a posterior cranial part fairly well developed for lodging the brain and an anterior facial part comprising mainly the jaws. The orbits are situated just behind the junction of the cranial and facial regions.

\section{The cranial region (Cranium)}

The various bones constituting the cranial region can be grouped into three segments, a posterior occipital segment, middle temporoparietal segment and an anterior frontal segment.

\subsection{The occipital segment (Os occipitale)}

It forms the posterior (nuchal) surface of the skull and the caudal part of the base of the cranium. It consists of four bones completely fused together and encircling a large passage, the foramen magnum, through which the spinal cord comes out. The supra-occipital makes the dorsal boundary of the foramen magnum. The ventral boundary is marked by a flat bone, the basi-occipital. The lateral boundaries are marked by a pair of exoccipitals. 


\subsubsection{The supraoccipital (1/19,} 211) represents the squamous part of the occipital bone (Squama occipitalis). It is flat shield-like with pitted surface. Its central part is distinctly quadrilateral and surrounded caudally and laterally by the nuchal crest. Rostrally it is separated from the two parietals by a small interparietal bone. On either side of the nuchal crest there is a deep Crescentric pitted depression. In addition, the external occipital protuberance $(2 / 3,9 / 6)$ extended in the median plane between the nuchal crest and the foramen magnum.

\subsubsection{The exoccipital (2/2), consti-} tutes the lateral part of the occipital bone (Pars lateralis).It bears a deep depression dorsally and an occipital condyle ventrally. The occipital condyles $(2 / 8)$ extended on both sides of the foramen magnum as prominent swellings and articulate with the atlas. The lateral margins of both the exoccipitals are protruded ventrally into prominent jugular processes (2/7). These processes closely applied over the tympanic bulla. The condyloid fossa (2/9) is deep, situated between the occipital condyle and the jugular process. It shows a double hypoglossal canal $(2 / 6)$.

1.1.3. The basioccipital $(2 / 3,3 / 10)$ represents the basilar part of the occipital bone (Pars basilaris) is short, wide and increases in thickness rostrally where it articulates with the basisphenoid. It is marked by a median longitudinal ridge and two small lateral muscular tubercles.

\subsection{The temporoparietal seg- ment:}

It consists of seven bones: a single triangular basisphenoid on the midventral side and a pair of alisphenoid and two temporals on either side as well as two parietals on the dorsal aspect.

1.2.1. Os basisphenoidale: the basisphenoid (3/11) has a broad posterior end connected with the basioccipitals by a thin plate of cartilage. It bears a longitudinal median ridge terminated nearly at the middle of the bone just behind the craniopharyngeal canal (Canalis craniopharyngeus). The latter canal (3/13) opened into the cranial cavity on the hypophyseal fossa.

1.2.2. Ala basispheoidale: the alisphenoids (6/40) form the wing of the basisphenoid. It is in the form of pitted plates, firmly united with the basisphenoid ventrally and with the temporal bones laterally. Each alisphenoid extend into the caudal orbital wall and it continues to the caudal borders of the palatine bone, where it forms the pterygoid process. 
1.2.3. Os temporale: the temporal bone (4/19) forms the greater portion of the lateral wall of the cranium, interposed between the alisphenoid and the parietal bone. It has a prominent zygomatic process which articulates with the zygomatic bone ventrally. The hollowed out ventral side of the zygomatic process forms the mandibular fossa which holds the condyle of the mandible. The temporal bone gives off the auditory capsule. The latter appears externally as a light, porous mastoid portion and a prominent flask-shaped tympanic bulla $(3 / 7,4 / 25,5 / 29)$. The neck of the flask constitutes the vertically oriented external acoustic meatus $(4 / 24,5 / 26)$ and its swollen base constitutes the tympanic bulla. The styloid process appears as a short and small projection ventral to the base of external acoustic meatus. The stylomastoid foramen is situated between the styloid and mastoid processes. The carotid canal is large and situated in the ventromedial part of the bulla tympanica. The jugular foramen appears ventrally between the bulla tympanica and the exoccipitals.

1.2.4. Os parietale: the parietal bones $(1 / 3,4 / 18)$ are a pair of thin slightly arched bones protecting the brain dorsally. Both the parietals are firmly united with each other by a suture along the mid-dorsal line. A

J. Vet. Anat. small interparietal bone separates the parietals from the supraoccipitals.

1.3. The frontal segment: This segment consists of five bones, the body of presphenoid ventrally, its two lateral wings (orbitosphenoids) and two frontals dorsally.

1.3.1. Os presphenoidale: the presphenoid $(3 / 14)$ is a thin, small bone situated on the ventral side of the cranium in front of the basisphenoid and connected with it by a cartilage. The presphenoid bone forms the ventral and anterior boundary of the optic foramen.

1.3.2. The orbitosphenoids $(4 / 29$, 5/11) form the wings of the presphenoid bone (Ala presphenoidale). They are in the form of wing-like plates of slightly bulging outwards and united with the presphenoid ventrally, the temporals caudally and the frontals dorsally by sutures. It forms part of the medial wall of the orbit.

1.3.3. Os frontale: the frontals (1/2) are large and strong bones protecting the brain from the dorsal side. Both frontals are united with each other by the interfrontal suture along the middle dorsal line. The frontals extend on the sides and taper anteriorly where they meet each other in the form of an inverted $V$-shape between the two nasal bones. Dorsally 
the lateral margin of each frontal forms the supraorbital process (1/7) as a prominent ridge over the orbit. The latter extend anteriorly and posteriorly where it forms the rostral and caudal supraorbital incisures.

The orbits (Orbita) are situated on the sides of the frontal segment of the cranial region. A median bony inter-orbital septum separates the two orbits, formed of the frontal, orbitosphenoid, alisphenoid and ethmoid bones. This median wall of the orbit contains the large optic foramen (4/28), where the two optic foramina of both sides are communicated rostrally into a single opening, and caudally they are connected with the cranium by a wide nearly circular orifice. It is worthy to mention that the optic axis forms nearly a right angle with the median plane, permitting a wide range of vision to rabbits as predators. The lateral sides of the orbit are protected by the zygomatic arch.

Os lacrimale : the lacrimal bones $(5 / 14)$ are located as small bones on the rostral surfaces of the orbit and did not appear on the dorsal surface but they extended laterally a little beyond the orbital rim. Each one contains a nasolacrimal canal which allows passage of the lacrimal duct. The ventrorostral part of the orbit is lodged by the maxillary tuber $(5 / 5)$. Between the latter and

J. Vet. Anat. the median wall of the orbit, the pterygopalatine fossa is present and contains the maxillary foramen (the entrance of the infraorbital canal), the sphenopalatine foramen (opens into the nasal cavity) and the caudal palatine (the entrance of the palatine canal). The ethmoid foramen appears as a small opening craniodorsal to the optic foramen. The orbital fissures are located ventral to the optic foramen on either side of the rostral part of the basisphenoid bone.

Os ethmoidale: the ethmoid boneis located in front of the cranial cavity and separates it from the nasal cavity. It presents a cribriform plate $(6 / 15)$ as a sieve-like bone through which the olfactory nerve fibers passes, and a small perpendicular plate $(6 / 14)$ which forms the caudodorsal part of the osseous nasal septum.

\section{The facial region}

The facial region is roofed above by the nasal bones, laterally by the incisive and maxillary bones and ventrally by the vomer.

2.1. Os nasale: the nasal bones ( 1 , $4 / 1 ; 5 / 2)$ are slightly convex from side to side. They have the same width along its length but their caudal ends are tapered laterally to receive the frontal bones. Rostrally, each nasal bone is notched and 
forms the dorsal boundary of the osseous nasal apertures. In the bisected skull, the nasal cavity is divided into right and left halves by the median vertical cartilaginous nasal septum. The latter is continued dorsally with the perpendicular plate of the ethmoid bone and is supported caudoventrally by the vomer bone.

Thin scroll-like extensions of the nasal, maxillary and ethmoid bones in the nasal passages constitute the dorsal turbinate $(6 / 11)$, ventral turbinate (6/12) and ethmoturbinate $(6 / 13)$ respectively. In the dissected specimens, the turbinate bones are covered by mucous membranes to form the nasal conchae. The dorsal turbinate are small situated dorsally forming the dorsal nasal concha (7/1). The ventral turbinate are rigid masses of bones that occupy the rostral portion of the lateral wall of the nasal cavity forming the ventral nasal concha (7/2) while ethmoturbinate forms the middle nasal concha $(7 / 3)$ and the ethmoidal conchae (7/4).

2.2. Os incisivum: the paired incisive bones (4/2) form the lateral and ventral wall of the nasal cavity rostral to the maxillaries. Each contains two incisor teeth in the rostral edge, a smaller incisor is situated caudally and a fairly large one is located ros- trally. The latter is characterized by a sagittal groove.

A long narrow nasal process $(4 / 3)$ is given out from each incisive bone, and extended caudodorsally along the lateral aspect of the nasal bone between the latter and the maxillary bone till it reached the nasofrontal suture. It concurs with the rostral free end of the nasal bone in forming the nasoincisive notch. A similar palatine process $(3 / 29)$ of the incisive bone passes caudally along with the palate and fused with its fellow of the opposite side they form the rostral part of the basis of the hard palate and surrounded laterally and caudally by the palatine fissure. The palatine fissure $(3 / 31)$ was very long and united with its fellow of the opposite side, a little rostral to the first premolar, to form a U-shaped fissure separating between the palatine process of the incisive and maxillary bones.

2.3. The maxilla $(4,5 / 4)$ as well as the incisive bones are the bones forming the nasal part of the upper jaw and both are connected together by sutures. The outer surface of the rostral half of the maxillary bonesforms the body of the maxilla ( Corpus maxillae) are pitted contains numerous foramina (4/5) which give it a trabeculated appearance.Among the latter, the infraorbital foramen $(4 / 7)$ is located. The caudal half of 
the maxillary bone bears a maxillary tuber $(4 / 8 ; 5 / 5)$ medially and a facial tuber $(1 / 6 ; 4 / 6)$ laterally. The former projects into the ventrorostral part of the orbit, while the latter extends caudally into the zygomatic process which fuses with the zygomatic process of the temporal bone as well as with the zygomatic bone to form the zygomatic arch. The alveolar process of the ventral portion of the maxillary bone contains the roots of two premolar and three molar teeth within the alveolar fossae.

In addition to the incisive and maxillary bones the paired temporal, palatine and pterygoid bones are also found in the upper jaw.

Os palatinum: the palatine bone has a perpendicular part (3/17) forming the lateral boundary of the choanae and a horizontal part (3/18) forming the caudal narrow portion of the basis hard palate Each palatine presents the rostral palatine foramen(3/27) on the level of the $3^{\text {rd }}$ premolar teeth, the rostral orifice of the palatine canal.

Os pterygoideum: the pterygoid bones are small, irregular bony plates situated behind the palatine bone and are joined with the alisphenoid by the two pterygoid processes (3/23) Each pterygoid process is excavated by a large pterygoid fossa (3/21) which sepa- rated the two pterygoidlaminae. The base of the lateral lamina was perforated by a large circular alar foramen.

Os zygomaticum: the zygomatic bones $(1 / 14,3 / 24,4 / 11,5 / 7)$ are paired bones that form the caudoventral part of the zygomatic arches. Each one fuses with the zygomatic process of the maxilla $(1 / 12,4 / 9,5 / 6)$ rostrally and articulates dorsally with the zygomatic process of the temporal bone $(1 / 13$, $4 / 31,5 / 8)$.

2.4. The vomer bone (3/15) forms the ventral portion of the median nasal septum, which divides the nasal cavity into right and left halves. It can be viewed through the palatine fissure.

\section{The lower jaw (Mandibula):}

The lower jaw consists of two halves which are united in front by the mandibular symphysis $(8 / 12$, 9/9). Each half consists of a body and a vertical ramus. The body is the thick horizontal part which bears sockets for the attachment of teeth. It can be divided into two parts; an incisive and a molar part. The incisive part $(8 / 1)$ is the thick part which form the symphysis and contain two sockets for the pair of incisors. The molar part $(8 / 2)$ is continuous caudally with the ramus of the mandible .Its alveolar border presents five 
sockets lodging the two premolars and three molar teeth. Just behind the last molar; the mandible presents a fairly large retroalveolar foramen $(8 / 9,9 / 6)$ which passes from the dorsal border to the medial side of the mandible.

The ramus of the mandible $(8 / 3)$ is thin and flat expanded bony plate for the attachment of jaw muscles .The ramus bears the condyloid process $(4 / 32,8 / 21,9 / 4)$ as a caudodorsal process for the articulation with the condyloid fossa of the zygomatic process of the temporal bone. Just in front of the condyloid process is the shallow mandibular notch $(8 / 20)$ demarcating the later process from the short blunt coronoid process $(8 / 19)$. The caudal and ventral border of the ramus is rounded and inflected upward to form an angular process (4/34, $8 / 17)$. In rabbits, the canine teeth are not found; therefore, there is a gap between the incisors and premolars forming long diastema or interalveolar border (8/13). The mandibular foramen $(8 / 10,9 / 8)$ was present on the medial surface caudoventral to the last molar tooth, while the mental foramen $(8 / 14,9 / 8)$ was situated on the body a little craniolateral to the first premolar.

Os hyoideum: the hyoid bone in the rabbit is formed of the body or basihyoideum, lingual process as well as the paired greater and lesser cornua. The basihyoideum $(10,11 / 1)$ is a wedge-shaped and situated just cranial to the body of the thyroid cartilage of the larynx. The lingual process $(10,11 / 4)$ is very short midventral projection embedded into the root of the tongue, giving attachment to the geniohyoid and genioglossus muscles. The greater cornua or thyrohyoideum (10/4 $11 / 2$ ) articulates with the lateral part of the basihyoideum and extends caudally for about $1.2 \mathrm{~cm}$ but does not articulate with the thyroid cartilage but attached by short thyrohyoid ligament. The lesser cornua or ceratohyoideum $(10,11 / 3)$ is attached to the dorsolateral part of the basihyoideumand extends nearly parallel to the thyrohyoideum for about $0.5 \mathrm{~cm}$ and also not articulated with any of the bones of the skull. It is to add that the jugulohyoid muscle is divided into two portions, dorsal (10/5) and ventral (10/6) that inserted into the free tip of the ceratohyoideum and thyrohyoideum respectively. It is therefore worthy to mention that the hyoid bone of the rabbit forms a sort of synsarcosis as its main connection to the bones of the skull is achieved by muscles so that a wide range of movability of the bone enabled. 


\section{Discussion}

In agreement with Crabb (1931) and Prasad (1969) the occipital bone was formed of four parts; the basioccipital forming the floor of the foramen magnum, the supraoccipital, forming the roof and the paired exoccipitals, forming the two sides of the foramen. Moreover, the foramen magnum was notched dorsally, in all the specimens, and each exoccipita Ibeared a deep depression just dorsal to the corresponding occipital condyle. A condition which was not recorded in the available literatures.

The present investigation revealed that the nasal bone was very long and had nearly equal width, except its most caudal part. The frontal bone lacked the zygomatic process but had rostral and caudal dorsolaterally situated supraorbital processes, and also extended ventrally to form part of the orbital wall. Similar findings were also recorded in the rabbit (Jordan and Verma, 1983; Barone, 1989 and Brewer, 2006). On the other hand De LullisandPulerà (2007) reported that the frontal bone of the cat was depressed at its middle and gave off a postorbital process to demarcate the posterior margin of the orbit. They also described a small triangular nasal bone, wide rostrally and narrow caudally.
Similar to the observations of Jordan and Verma (1983), Wingerd (1985), Barone (1989) and Brewer (2006) the zygomatic arch was formed by fusion of the zygomatic process of the maxillary bone and the rostral end of the zygomatic bone. Caudodorsally, the arch articulated with the zygomaticprocessof the temporal bone. Brewer (2006) added that there is no retroarticular process preventing retropulsion of the mandibular condyle of the rabbit as in dog and cat. However, the zygomatic arch was elongated in the rabbit and projected alongside the lateral aspect of the condyloid process of the mandible. This extended the surface area available for the attachment of the temperomandibular joint capsule providing an additional lateral support to the joint, a result that explained the caudal extension of the zygomatic bone beyond its articulation with the zygomatic process of the temporal bone.

The two optic canals present in most mammals were represented in the present study by a single, large circular optic foramen which was communicated, at the same time, with the two orbits and with the cranial cavity, a result which was in agreement with the description of Jordan and Verma (1983), Wingerd (1985), and Brewer (2006). In the present investigation, the cephalic wall of the orbit was formed ventral- 
ly from the maxillary tuberosity and dorsally by the lacrimal bone. The former appeared as a thick bony mass due to the dorsal extension of the teeth, it bounded the pterygopalatine fossa laterally. The lacrimal bone did not appear on the dorsal surface but it extended laterally beyond the orbital rim. A condition which was peculiar to the rabbit skull and was similar to the observation of Jordan and Verma (1983), Wingerd (1985).

The nasal process of the incisive bone was well developed and extended dorsocaudally along the lateral aspect of the nasal bone till the nasofrontal suture separating between the nasal and maxillary bones. A condition which was peculiar to rabbit skull and simulated the observation of Jordan and Verma (1983) and Barone (1989).

The present study revealed that the incisive bones were well developed in the rabbit. On each one, there was a strong grooved incisor backed by another small incisor. Moreover, the interincisive canal as well as the canine tooth were absent in the rabbit, a result which was also reported by Barone (1989) and Brewer (2006). On the other hand, De Lullis and Pulerà (2007) recorded that the incisive bone was a fairly small bone in cats. They described three incisors in each incisive be- side a large curved canine in the maxilla.

The palatine fissure was very long and united with its fellow of opposite side, a little rostral to the first premolar, to form a U-shaped fissure separating between the palatine process of the incisive and maxillary bones. The latter were notched rostrally by the caudal end of the palatine fissure, a result which was in accordance with Jordan and Verma (1983) and Barone (1989) in rabbits. On the contrary, the palatine fissure was very small in cats, where the palatine processes of the incisive and maxillary bones were continued and constitute the osseous portion of the hard palate, (De Lullisand Pulerà, 2007).

The body of the basisphenoid bone was perforated completely by the craniopharyngeal canal which opened into the cranial cavity on the hypophyseal fossa. A condition which form a peculiar character for rabbit skull and simulated the observation of Barone (1989). On the other hand, Jordan and Verma (1983) named it as pituitary foramen while Brewer (2006) named it as foramen cavernosum.

The present investigation recorded that the tympanic bulla was more rounded and did not projected ventrally beyond the level of the occipi- 
tal bone as it did in dog and cat ( King et al., (2007) . The later authors added that, the mastoid process was represented by a small bone protrusion caudal to the external acoustic meatus, while the jugular process was poorly developed. Being much less prominent than in the rabbit, these structures did not interfere with ultrasound imaging of the tympanic bulla in the dog and cat.

The external acoustic meatus of the rabbit was vertically rather than horizontally oriented and took the form of a prominent base tube compared to the short bone canal of the dog (King et al.; 2007) while the cat had little more than a bone ring. The wall of the tympanic bulla was reported to be thicker in the rabbit than in the dog and cat (Deeb, 1997). Similar observations were recorded in the present investigation.

Concerning the mandible the present study revealed that condyloid process was more expanded and raised higher than the coronoid process, on the contrary to the observation of $\mathrm{De}$ Lullis and Pulerà (2007) in the cat who recorded that the coronoid process was the largest and extending dorsally. The retroalveolar foramen peculiar to rabbit was situated on the cranial border of the ramus just caudal to the last tooth. In addition, the alveoli for the canine teeth were absent, resulting

J. Vet. Anat. in a large diastema, a result which was in agreement with Crabb (1931) and Prasad (1969).In accordance with Chow et al., (2009), the rabbit mandible formed a semicircular mandibular angle that protruded ventrally. Preventing the external palpation the tympanic bulla.

The present study revealed that the anatomy of the hyoid bone in the rabbit differed greatly from that in other mammals in that the stylohyoid components of the hyoid bone was lacking and the bone was formed only ofthe body or basihyoideum, the greater cornua or thyrohyoideum and the lesser cornua or ceratohyoideum . Similar findings were reported in the rabbit by Barone et al., (1973) and little and Lane (1986). However the latter authors mentioned that the thyrohyoideum and ceratohyoideum articulated with the thyroid cartilage and jugular process of the occipital bone respectively, an observation which could not be matched favorably with the present finding which revealed that the hyoid bone didn't articulate with the bones of the cranium and its main connection to the these bones was through muscles.

\section{References}

Barone, R., (1989): Anatomie Comparée des Mammifères Domestiques, third Ed

Vol 5 No 2, (2012) 49 - 70 
Vigot, Paris.

Barone, R., Pavaux, C., Blin P.C. and Cuq, P., (1973): Atlas of Rabbit Anatomy (Masson et Cie, Paris), 11-50

Brewer, N.R. (2006): Historical Special Topic Overview on Rabbit Comparative Biology Journal of the American Association for Laboratory Animal Science Vol 45, No 1 January 2006 Pages 8-24.

Chow, E.P., Bennett, R.A. and

Dustin, A.L. (2009):

Ventral Bulla Osteotomy for treatment of otitis media in a Rabbit. Journal of Exotic pet medicine, 2009.

Crabb, E.D. (1931): Principles of functional anatomy of the rabbit. P. Blackstone's son \& co., Inc., 1931.

Deeb, B.J., (1997): Respiratory disease and the Pasteurella complex In: Hillyer, E.V., Quesenbery, K.E. (Eds.), Ferrets, Rabbits and Rodents. Clinical Medicine and Surgery. W.B. Saunders, Philadelphia, pp. 189-201.

De Lullis, G. and Pulerà, D. (2007):

The dissection of vertebrates: a laboratory manual. ISBN 0120887762, 9780120887767

Harrison, B.M. (1976): The dissect tion of the cat and comparisons with man: a laboratory manual on felisdomestica (Second Edition).

Hefti, E., Trechsel, U., Rfifenacht, H. and Fleisch, H. (1980): Use of Dermestid Beetles for Cleaning Bones Calcif. Tissue, Int. 31, 45-47 (1980)

Hildebrand, M. (1968): Anatomical preparations, Berkelely and Los Angeles: University of California press

Jordan, E.L. \& Verma, P.S. (1983):

Chordate zoology and Elements of animal physiology. S.CHAND \& COMPANY LTD, RAMNAGAR, NEW DELHI

King, A.M., Cranfield, F., Hall, J., and Sullivan, M., (2007): Anatomy and ultrasonographic appearance of the tympanic bulla and associated structures in the rabbit. The Veterinary Journal 173, 512-521.

Little, C.J., \& Lane, J.G., (1986):

The surgical anatomy of the feline bulla tympanica. Journal of Small Animal Practice 27, 371-378.

Meredith, A. (2009): Rabbits, Royal (Dick) School of Veterinary Studies, University of Edinburgh<http://www.aquavet.i1 2.com/Rabbit.htm $>$ (accesse d 02.04.09).

Nicholson, M. (2001): British Rab- 
bit Co cil.<www.thebrc.org/ index.html $>$ (Accessed 02.04.09)

Nomina Anatomica Veterinaria (2005):5th Ed. prepared by the International Committee on Veterinary Gross Anatomical Nomenclature (I.C.V. G.A.N.) and authorized by the General Assembly of the World Association of Veterinary Anatomists (W.A.V.A.), Knoxville, TN, USA. Published by the Editorial Committee, Hannover, Columbia, Gent, and Sapporo

Prasad, S.N. (1969): A laboratory manual of vertebrate zoology. Rec Id: 11287720, Allahabad: Pustakayan

Rolleston, G. and Jackson, W.H.

(1898): Chapter 4: Cervical, Dorsal, Lumbar, Sacral, and Caudal Vertebrae of Rabbit (Lepus.cuniculus).From the book "Forms of Animal Life: a manual of comparative anatomy, with descriptions of selected types" "2nd Ed. Publisher: Oxford: Clarendon Press. OCLC Number: 47728498

Russell, W.C. (1933): Dermestid beetles as an aid in cleaning bones.J. Mamm., Vol. 14, no. 4, pp. 372-374, 1933.
Russell, W.C. (1947): Biology of dermestid beetles with reference to skull cleaning. Jour. Mamm., Vol. 28, no. 3, pp. 384-387, 1947.

Shively, M.J. (1979): Xeroradiographic anatomy of the domesticated rabbit (Oryctolagu scuniculus) Part I: head, thorax and thoracic limb. The Southwestern Veterinarian 32, 219-233.

Sommer, H.G. and Anderson, S. (1974): Cleaning skeletons with dermestid beetles, two refinements in the methodCurator, 17:290-298.

Sullivan, L.M. \& Romney, and October, C.P. (1999): Cleaning and Preserving Animal Skulls. The University of Arizona Cooperative Extension. http://ag.arizona.edu/ pubs/ natresources/az1144.pdf

Wake, M.V. (1992): Hyman's comparative vertebrate anatomy (Third Edition) University of Chicago Press ISBN: 0226870138, 9780226870137

Wingerd, B.D. (1985): Rabbit Dissection Manual.The Johns Hopkins University Press, Baltimore. 
Fig (1): A photograph showing the dorsal view of the skull of the rabbit.

1- Os nasale..

2- Os frontale.

3- Os parietale.

4- Processus nasalis os incissivum.

5- Os lacrimale.

6- Tuber faciale.

7- Margo supraorbitalis.

8- Rostral branch of 7.

9- Caudal branch of 7.

10- Incisura supraorbitalis Rostralis.

11- Incisura supraorbitalis caudalis.

12- Processus zygomaticus os maxillae.

13- Processus Zygomaticus os temporale.

14- Os zygomaticum.

15- Meatus acusticus axternus.

16- Pars squamosa os temporale

17- Crista sagittalis externa.

18- Os interparietale

19- Squamosa occipitalis.

20- Crista nuchae.

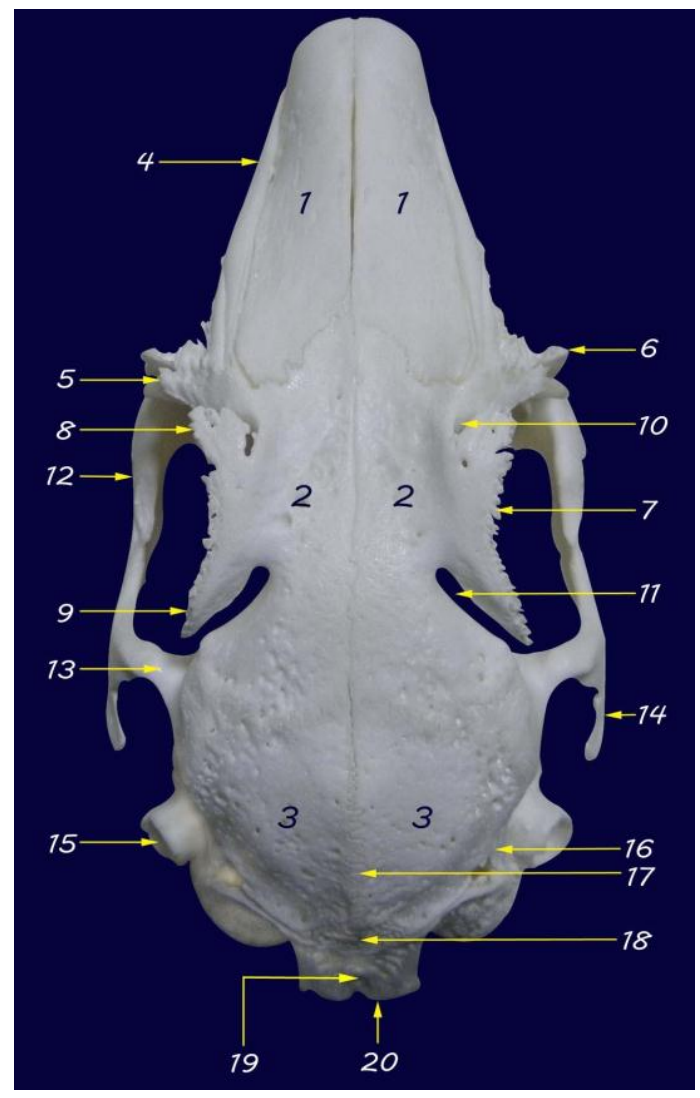

Fig (2): A photograph showing the nuchal surface of the occipital bone of the rabbit.

1- Squama occipitalis.

2- Pars lateralis os occipitale..

3- Pars basilaris os occipitale.

4- Foramen magnum.

1- Crista nuchae.

2- Protuberantia occipitalis externa.

7- Processus jugularis.

8- Condylus occipitalis.

9- Fossa condylaris ventralis.

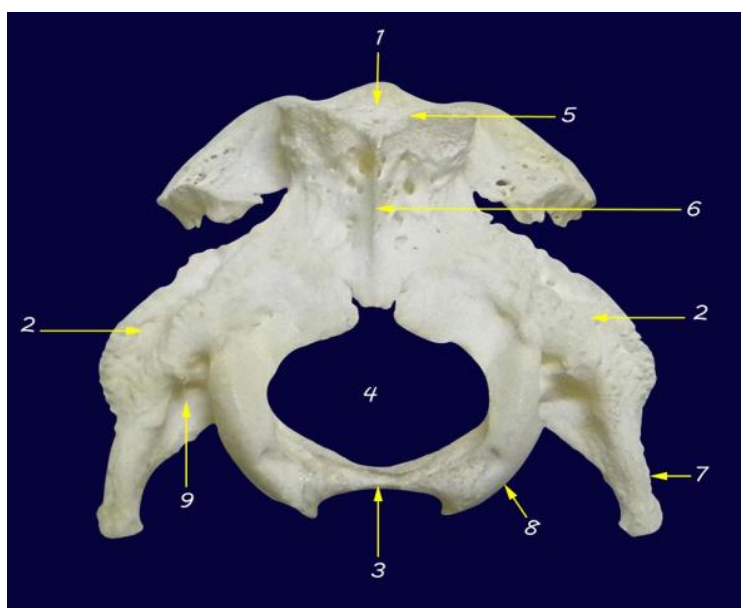


Fig (3): A photograph showing the ventral view of the skull of the rabbit.

1- Foramen magnum.

2- Crista nuchae.

3- Protuberantia occipitalis externa.

4- Condylus occipitalis

5- Processus jugularis.

6- Canali n. hypoglossi.

7- Bulla tympanica.

8- Foramen jugulare.

9- Canalis caroticus.

10- Pars basilaris os occipitale.

11- Os basisphenoidale.

12- Tuberculum basilaris.

13- Canalis craniopharyngeus.

14- Os presphenoidale.

15- Vomer.

16- Fissura orbitalis.

17- Lamina perpendicularis os palatinum.

18- Lamina horizontalis os palatinum.

19- Choanae.

20- Margo supraorbitalis.

21- Fossa pterygoidea.

22- Ala presphenoidale.

23- Processus pterygoideus.

24- Os zygomaticum.

25- Tuber faciale.

26- Prossesus palatinus of maxilla.

27- Foramen palatinum majus.

28- Corpus ossis incicivi.

29- Prossesus palatinus of 28.

30- Os conchae nasalis ventralis.

31- Fissura palatinus.

32- Dentes incisive

33- Processus alveolaris of 28.

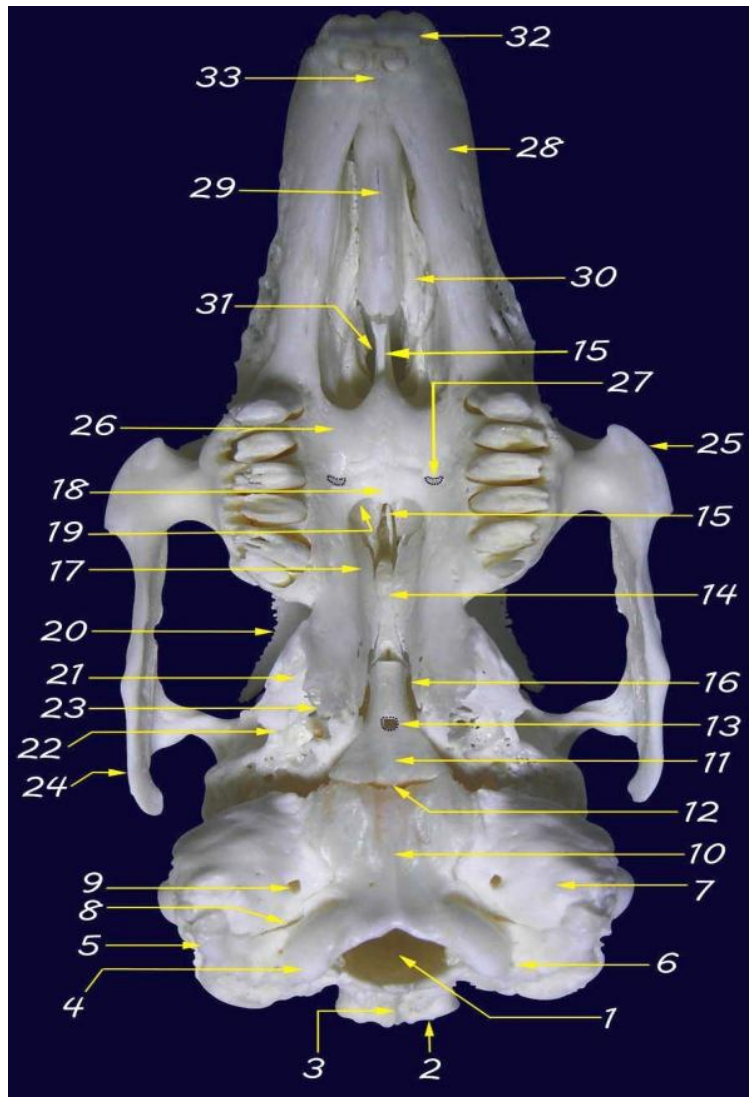




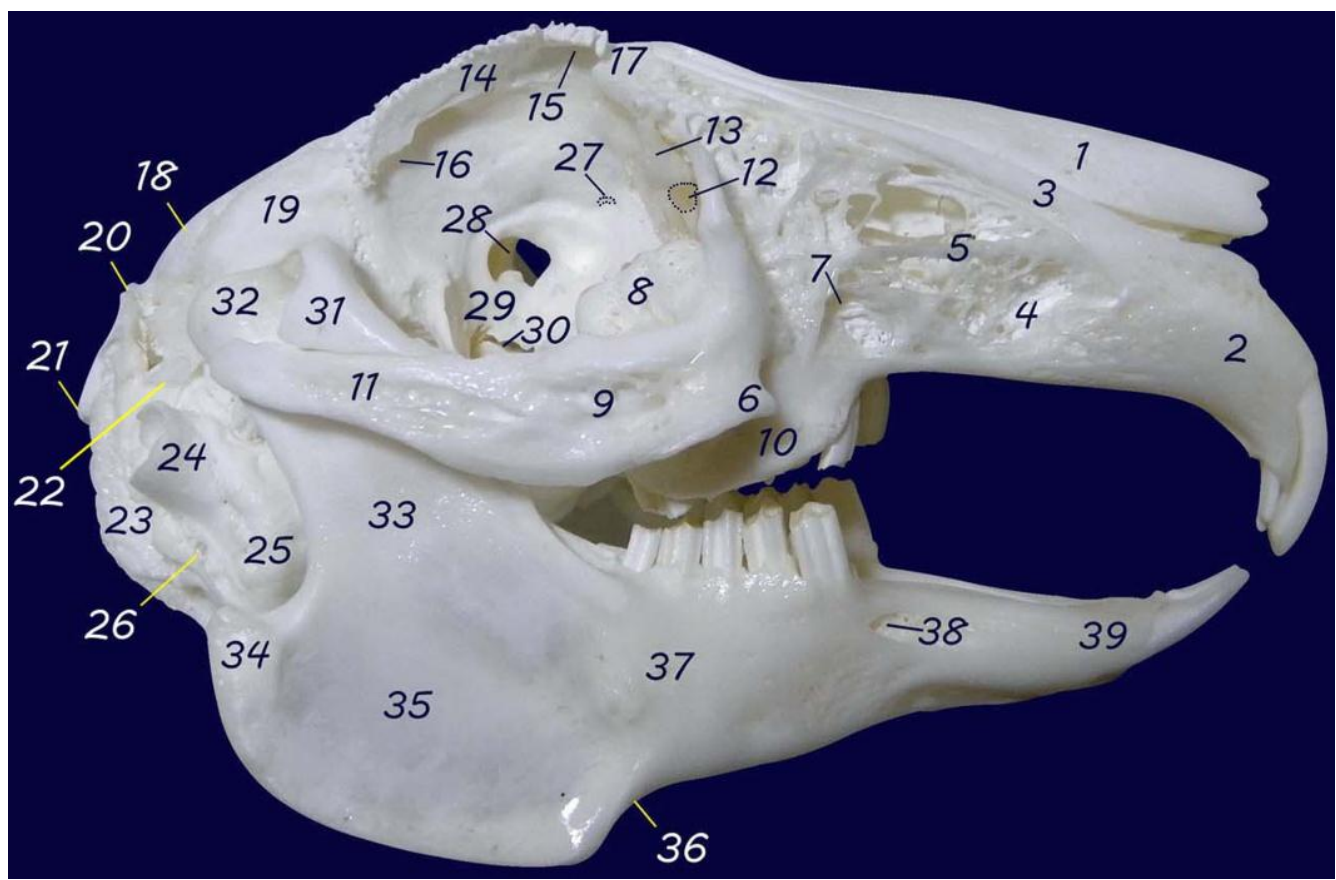

Fig (4): A photograph showing the right lateral view of the skull and mandible of the rabbit.

\begin{tabular}{|l|l|}
\hline 1- Os nasale. & 21- Crista nuchae \\
2- Corpus ossis incicivi & 22- Processus retrotympanicus. \\
3- Processus nasalis os incissivum. & 23- Processus mustoideus. \\
4- Corpus maxillae (maxilla). & 24- Meatus acusticus axternus. \\
5- Facies facialis of 4(perforated). & 25- Bulla tympanica. \\
6- Tuber faciale. & 26- Foramen stylomastoideum. \\
7- Foramen infraorbitale. & 27- Foramen ethmoidale. \\
8- Tuber maxillae. & 28- Canalis opticus. \\
9- Processus zygomaticus of 4 & 29- Ala presphenoidale. \\
10- Juga alveolaris of 4 & 30- Fissura orbitalis. \\
11- Os zygomaticum & 31- Processus Zygomaticus os temporale \\
12- Foramen lacrimale. & 32- Processus condylaris. Of mandible \\
13- Os lacrimale. & 33- Ramus mandibulae. \\
14- Margo supraorbitalis & 34- Processus angularis. \\
15- Incisura supraorbitalis Rostralis & 35- Fossa masseterica. \\
16- Incisura supraorbitalis caudalis & 36- Incisura vasorum facialium. \\
17- Margo nasalis os frontale & 37- Corpus mandibulae \\
18- Os parietale. & 38- Foramen mentale. \\
19- Os temporale. & 39- Pars incissiva of 37. \\
20- Os interparietale & \\
\hline
\end{tabular}




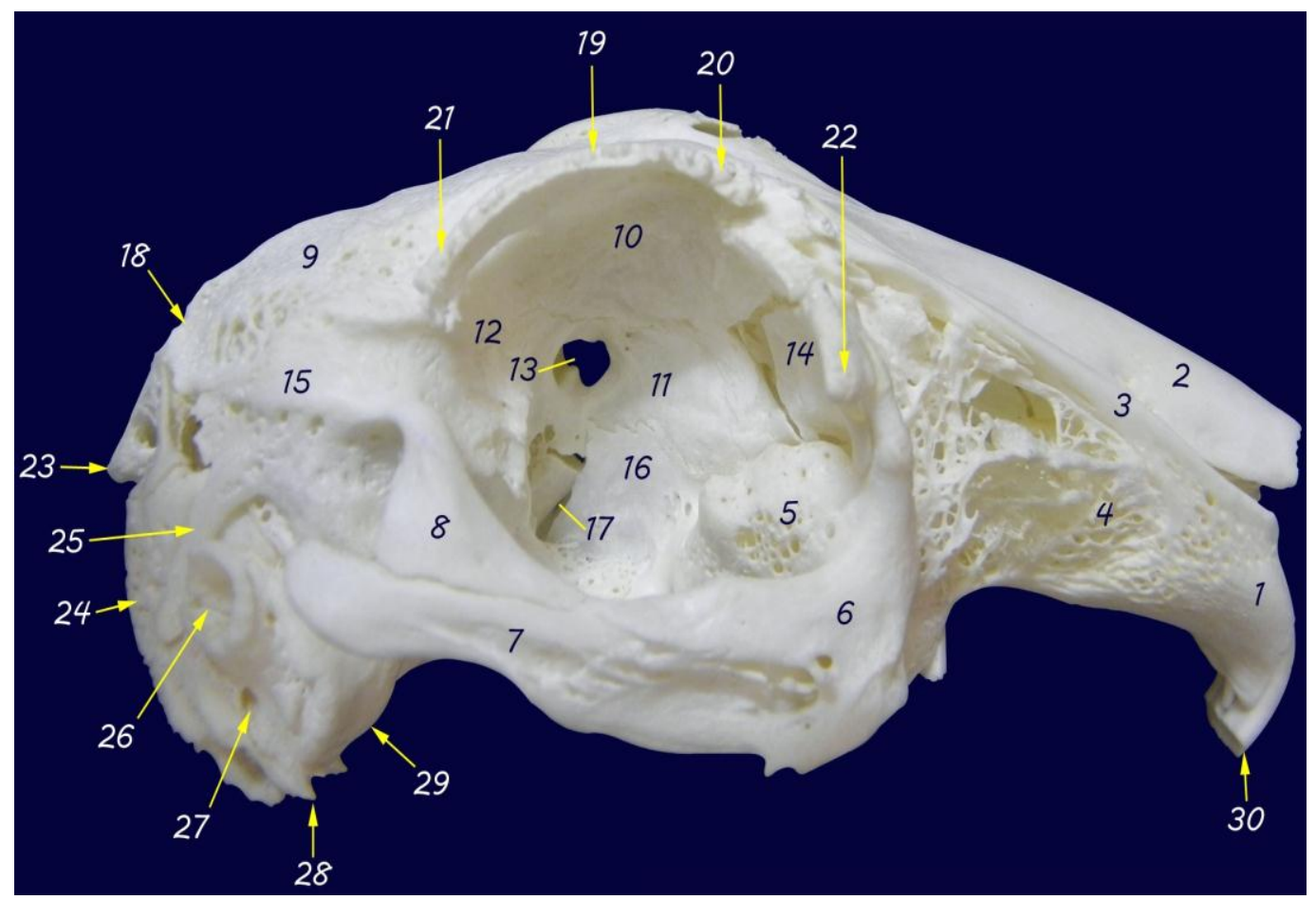

Fig (5): A photograph showing the right lateral view of the skull of the rabbit.

\begin{tabular}{|l|l|}
\hline 1- Corpus ossis incicivi & 16- Lamina perpendicularis os palatinum. \\
2- Os nasale & 17- Fissura orbitalis. \\
3- Processus nasalis os incissivum & 18- Os interparietale \\
4- Corpus maxillae (maxilla). & 19- Margo supraorbitalis. \\
$5-$ Tuber maxillae. & 20- Rostral branch of of 19. \\
6- Processus zygomaticus of 4. & 21- Caudal branch of 19. \\
7- Os zygomaticum. & 22- Os lacrimale. \\
8- Processus Zygomaticus os temporale. & 23- Crista nuchae. \\
9- Os parietale. & 24- Processus mustoideus. \\
10- Os frontale (Pars orbitalis). & 25- Processus retrotympanicus. \\
11- Ala presphenoidale. & 26- Meatus acusticus axternus. \\
12- Os temporale(Pars orbitalis). & 27- Foramen stylomastoideum. \\
13- Canalis opticus. & 28- Processus jugularis. \\
14- Os lacrimale. & 29- Bulla tympanica. \\
15- Os temporale & 30- Dentes incisivi \\
\hline
\end{tabular}




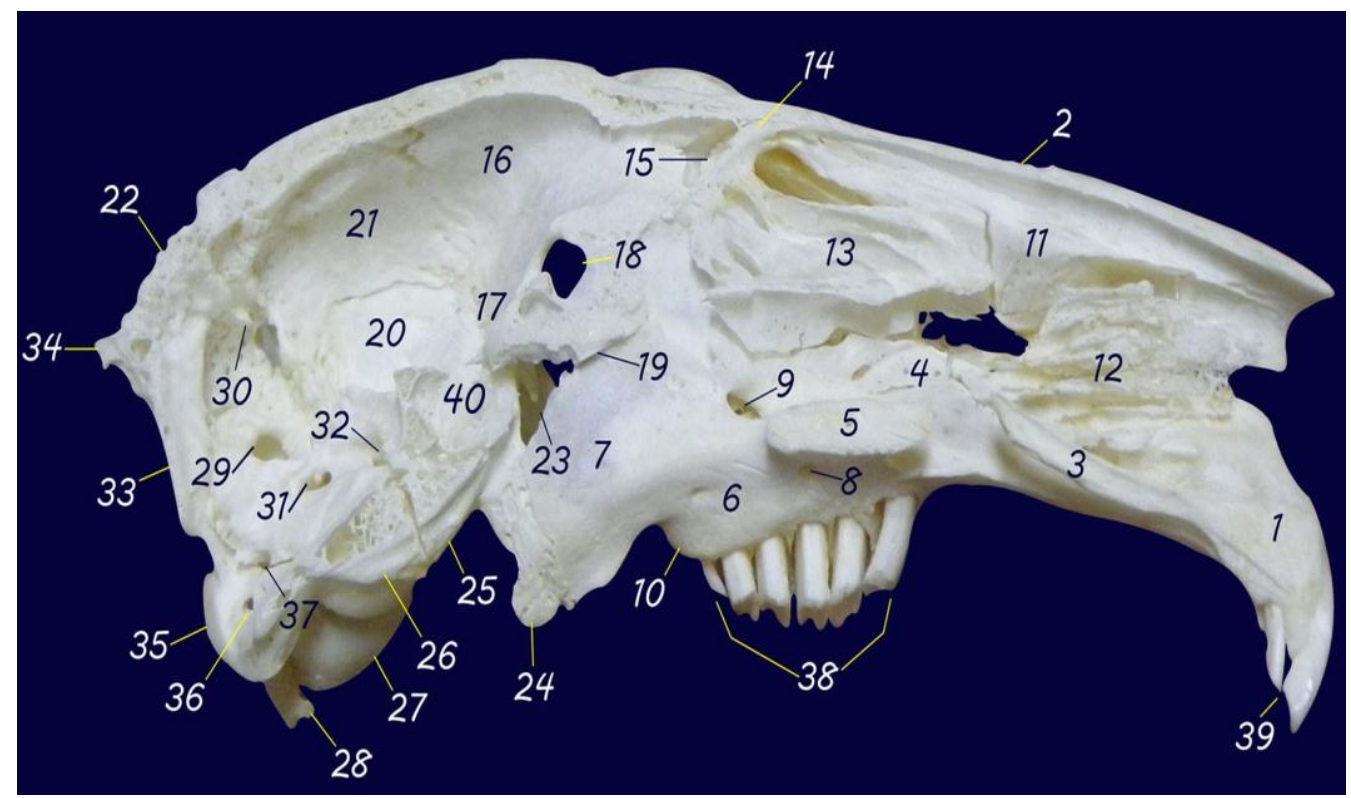

Fig (6): A photograph showing the sagittal section of the left half of the skull of the rabbit.

\begin{tabular}{|c|c|}
\hline 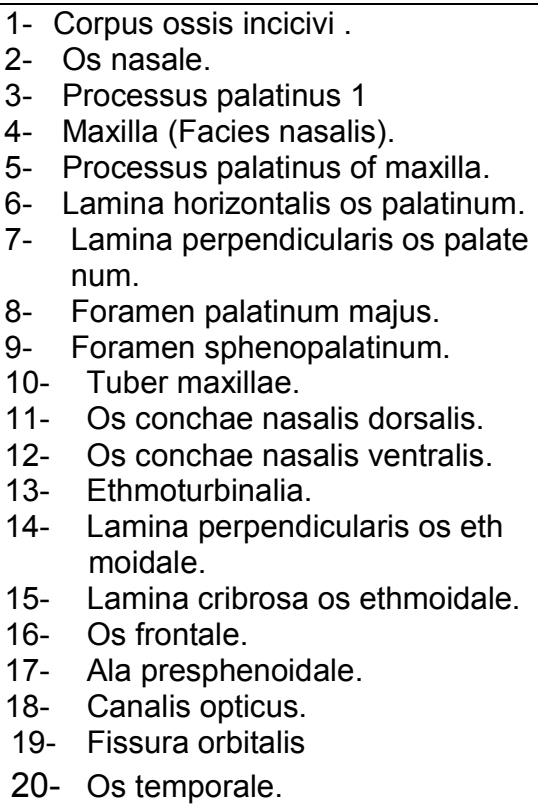 & $\begin{array}{l}\text { 21- Os parietale. } \\
\text { 22- Os interparietale. } \\
\text { 23- Ala presphenoidale (Fragile part). } \\
\text { 24- Processus pterygoideus. } \\
\text { 25- Os basisphenoidale. } \\
\text { 26- Pars basilaris os occipitale. } \\
\text { 27- Bulla tympanica. } \\
\text { 28- Processus jugularis. } \\
\text { 29- Fossa cerebellaris. } \\
\text { 30- Tentorium cerebelli osseum.. } \\
\text { 31- Meatus acusticus internus. } \\
\text { 32- Canalis n. trigemini. } \\
\text { 33- Protuberantia occipitalis externa. } \\
\text { 34- Crista nuchae. } \\
\text { 35- Condylus occipitalis } \\
\text { 36- Canali n. hypoglossi. } \\
\text { 37- Foramen jugulare. } \\
\text { 38- Dentes premolares and molares. } \\
\text { 39- Dentes incisivi. } \\
\text { 40- Ala presphenoidale. }\end{array}$ \\
\hline
\end{tabular}




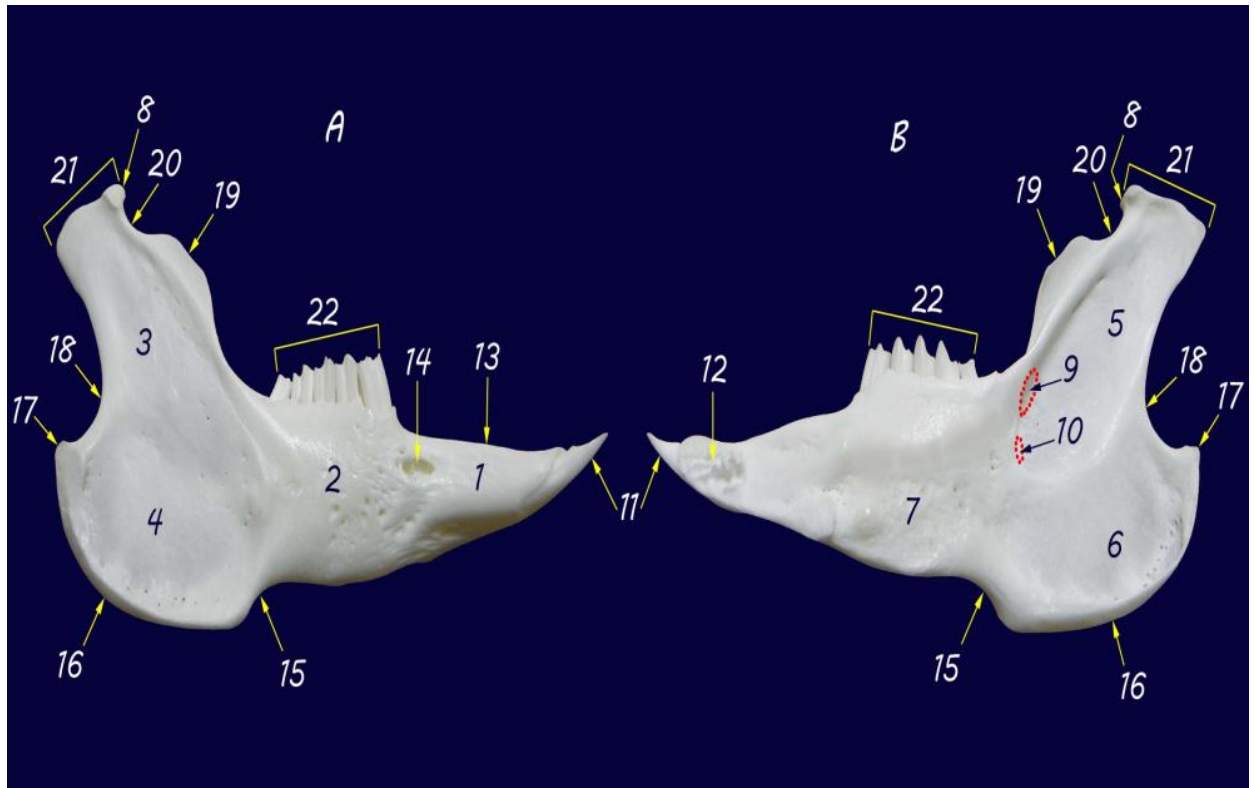

Fig (7): A photograph showing the lateral (A) and Medial (B) views of the right half of the mandible of the rabbit.

\begin{tabular}{|c|c|}
\hline $\begin{array}{ll}\text { 1. } & \text { Corpus mandibulae (Pars incis- } \\
\text { siva). } \\
\text { 2. Corpus mandibulae (Pars mola- } \\
\text { ris). } \\
\text { 3. } \\
\text { 4. } \text { Fomus mandibulae. } \\
\text { 5. Fovea masseterica. } \\
\text { 6. Fossa pterygoidea. } \\
\text { 7. } \\
\text { 8. } \text { Pacies lingualis. } \\
\text { 9. } \\
\text { 10. } \\
\text { Foramen retroamen mandibulae. }\end{array}$ & $\begin{array}{l}\text { 11- Incisura mandibulae. } \\
\text { 12- Symphysis mandibulae. } \\
\text { 13- Margo interalveolaris. } \\
\text { 14- Foramen mentale. } \\
\text { 15- Incisura vasorum facialium. } \\
\text { 16- Angulus mandibulae. } \\
\text { 17- Processus angularis. } \\
\text { 18- Collum mandibulae. } \\
\text { 19- Processus coronoideus. } \\
\text { 20- Incisura mandibulae. } \\
\text { 21- Processus condylaris. } \\
\text { 22- Dentes premolares and molares. }\end{array}$ \\
\hline
\end{tabular}




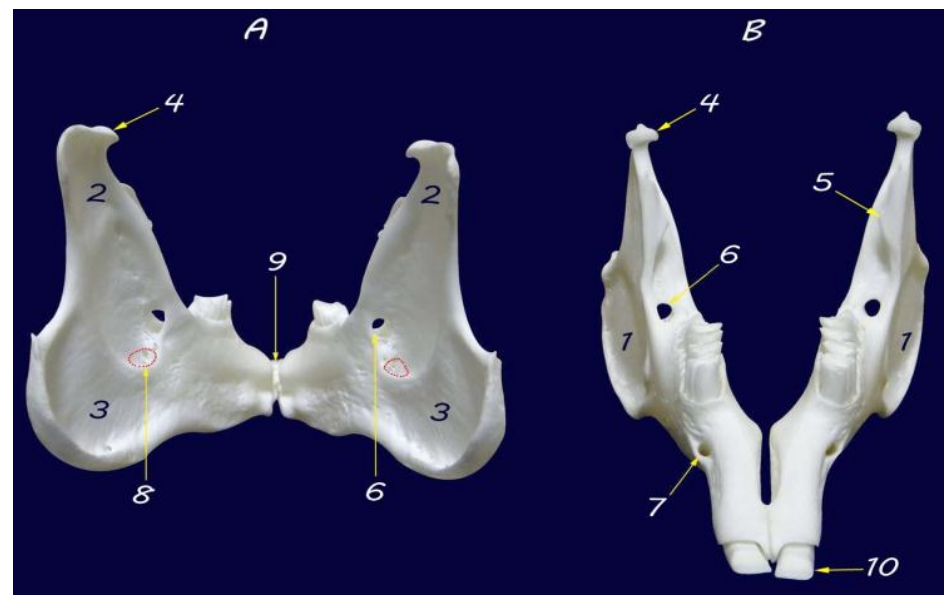

Fig (8): A photograph showing the caudal (A) and rostral (B) views of the mandible of the rabbit

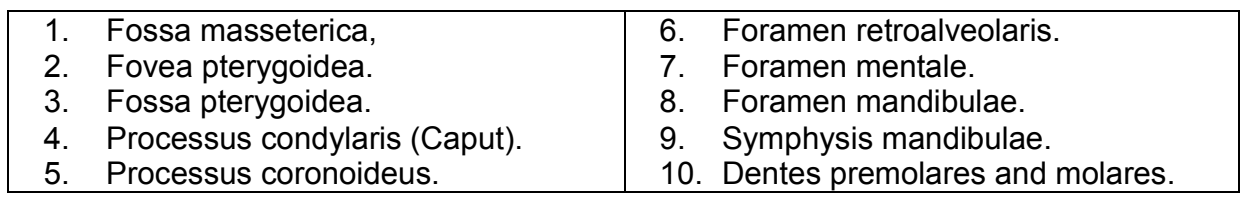

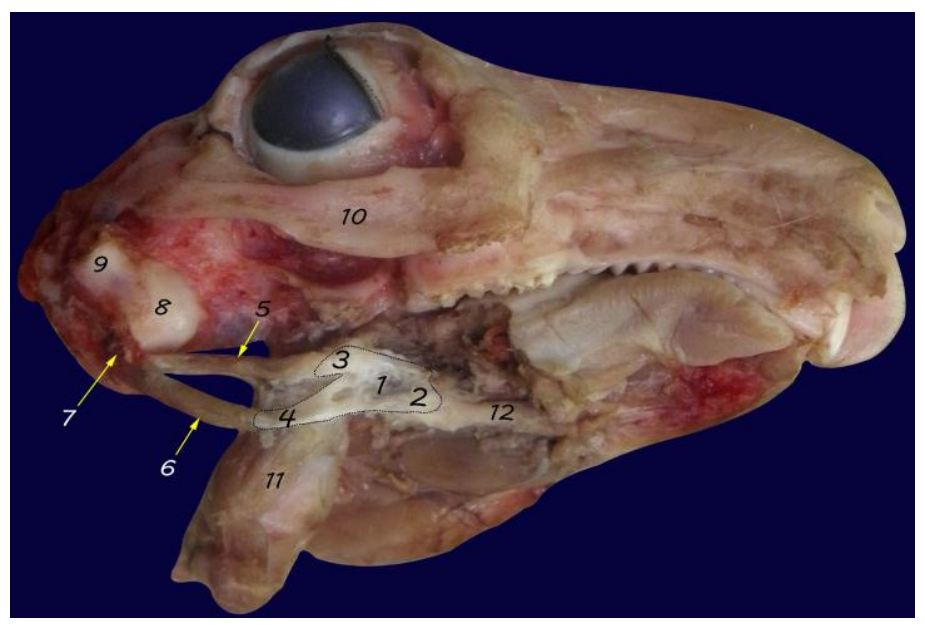

Fig (9): A photograph showing the hyoid apparatus of the rabbit in situ (Dissected right side of the head. Dotted lines indicate the boundaries of the hyoid bone.

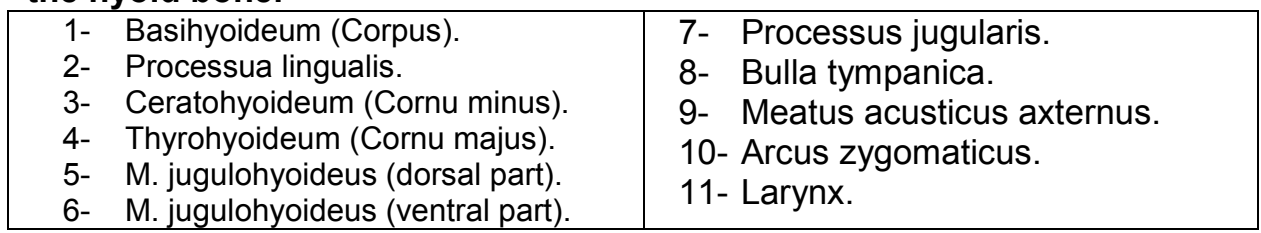




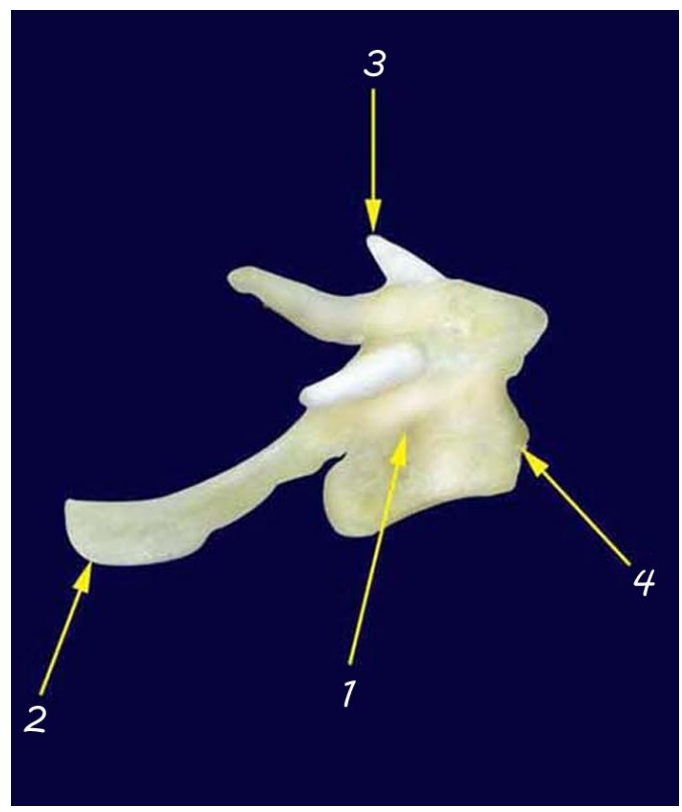

Fig (10): A photograph showing a dorsolateral view of the hyoid apparatus of the rabbit.

\begin{tabular}{|c|c|}
\hline $\begin{array}{ll}\text { 1- } & \text { Basihyoideum (Corpus). } \\
\text { 2- } & \text { Thyrohyoideum (Cornu majus). }\end{array}$ & $\begin{array}{l}\text { 3- } \begin{array}{l}\text { Ceratohyoideum (Cornu } \\
\text { minus). }\end{array} \\
\text { 4- Processua lingualis. }\end{array}$ \\
\hline
\end{tabular}

